\title{
Acute aerobic exercise effects on cognitive function in breast cancer survivors: a randomized crossover trial
}

\author{
Elizabeth A. Salerno ${ }^{1,2^{*}}$ D, Kendrith Rowland ${ }^{3}$, Arthur F. Kramer ${ }^{2,4}$ and Edward McAuley ${ }^{2}$
}

\begin{abstract}
Background: Many breast cancer survivors (BCS) report deficits in cognitive function. Physical activity (PA) has been associated with better processing speed and memory in healthy adults and thus may be a useful method for improving cognition in BCS. The purpose of this study was to examine the effects of an acute bout of PA on processing speed and spatial working memory in a sample of BCS.

Methods: Using a repeated measures, crossover design, BCS [N=27; $\left.M_{\text {age }}(\mathrm{SD})=49.11(8.05)\right]$ completed two sessions in counterbalanced order: 30 min of moderate-intensity treadmill walking and 30 min of seated rest. Women completed cognitive tasks immediately before and after each session.

Results: Within-subjects repeated measures analyses of variance revealed a significant time by session effect for processing speed reaction time $[\mathrm{F}(1,25)=5.02, p=.03, \eta 2=0.17]$. This interaction was driven by significantly reduced reaction time (e.g., faster response) post-exercise and no change post-rest. Further between-subjects analyses indicated a significant time by session by moderate to vigorous physical activity (MVPA) split $[F(1,25)=5.23, p=.03, \eta 2=0.17]$, such that women who engaged in $\geq 45$ min of average daily MVPA reduced their reaction time post-exercise $(p=.01)$ and increased RT post-rest $(p=.06$ ). Time by session effects for spatial working memory 3 -item accuracy and 4 -item reaction time trended towards significance, $p=0.08$ and $p=0.10$, respectively, again driven by better performance post-exercise.
\end{abstract}

Conclusions: The moderate effect of acute exercise on domains of memory and processing speed in BCS is encouraging. Cancer-related cognitive impairment remains largely misunderstood; however, the results from the present study offer preliminary evidence for the positive relationship between acute exercise and cognition in BCS.

Trial registration: ClinicalTrials.gov NCT02592070. Registered 30 October 2015. Retroactively registered.

Keywords: Breast cancer, Acute exercise, Cognitive function, Survivorship

\section{Background}

Breast cancer mortality in the United States has been declining over the past two decades [1, 2]; however, the incidence of breast cancer is steadily rising with an estimated 1 in 8 women expected to develop the disease over the course of her lifetime [1]. Consequently, the number of women living with a history of breast cancer is expected to reach 4 million by the year 2020 [3]. While effective in improving survival rates $[4,5]$, cancer treatment is associated with a host of

\footnotetext{
* Correspondence: elizabeth.salerno@nih.gov

${ }^{1}$ Cancer Prevention Fellowship Program, Division of Cancer Epidemiology \& Genetics, Metabolic Epidemiology Branch, National Cancer Institute, Bethesda, MD 20892, USA

${ }^{2}$ University of Illinois at Urbana-Champaign, Champaign, USA

Full list of author information is available at the end of the article
}

deleterious health consequences, ranging from reduced physical function to increased risk of developing comorbid diseases $[6,7]$. One such detriment is impaired cognitive function, highlighted by the National Coalition for Cancer Survivorship as a significant quality of life concern for cancer survivors [8].

Cancer-related cognitive impairment (CRCI) has been defined in the literature as the loss of mental acuity associated with cancer and its subsequent treatment [9]. Working memory, the act of holding information in one's mind and manipulating it, and processing speed, the speed with which one interprets information [10], have both been identified as important determinants of long-term survival in cancer survivors [11-13]. Unfortunately, these are the

(c) The Author(s). 2019 Open Access This article is distributed under the terms of the Creative Commons Attribution 4.0 International License (http://creativecommons.org/licenses/by/4.0/), which permits unrestricted use, distribution, and 
same cognitive processes most commonly reported by survivors to be negatively affected throughout their cancer experience [14]. Janelsins and colleagues [15] reported that CRCI can be detected in up to $30 \%$ of patients prior to treatment, $75 \%$ during treatment, and $35 \%$ up to a decade post-treatment. The etiology of CRCI in breast cancer remains unclear, but is hypothesized to be multi-factorial with influence from genetic, psychosocial, treatment-specific (e.g., chemotherapy), and behavioral factors, among others $[15,16]$. It is also theorized that cancer and its treatment accelerate the aging process, initiating cognitive decline sooner in survivors than the general population [17]. As such, there's a burgeoning need to identify effective and low-cost methods for improving cognitive and brain health in this cancer cohort to ultimately improve quality of life during survivorship.

Physical activity (PA) is a lifestyle behavior that has been consistently associated with improved physical, cognitive and mental health across the lifespan [18]. Recent work has attempted to understand the effects of chronic exercise training on cognition in cancer survivors with mixed, albeit tentatively promising, results [19-21]. Unfortunately, breast cancer survivors generally fail to meet federal recommendations for PA [22]. Given the many difficulties survivors face in initiating and maintaining an exercise regimen (e.g., fatigue, pain), acute PA, or single exercise sessions, may be a more achievable and salient target for a subset of this cohort, particularly if immediate health improvements can be evidenced.

The recent release of the 2nd edition of the Physical Activity Guidelines for Americans in 2018 has highlighted strong evidence for acute PA in improving cognition across the lifespan [23]. In healthy adults, a meta-analysis by McMorris and colleagues [24] found significant improvements in reaction time on working memory tasks following acute bouts of moderate-intensity PA. Similarly, another meta-analysis [25] in disease-free individuals found a small, positive effect of acute aerobic exercise on varying domains of cognition across the lifespan. In breast cancer survivors specifically, several studies have indicated that an acute bout of exercise may improve psychological and physical health components [26-28]. Despite the documented evidence of acute exercise benefits, to our knowledge, no study to date has examined the cognitive effects of acute exercise in breast cancer survivors specifically.

The primary aim of the present study was to examine the effects of a 30-min moderate-intensity aerobic exercise session on processing speed and spatial working memory compared with $30 \mathrm{~min}$ of quiet, seated rest in breast cancer survivors. Because of previous work demonstrating acute exercise benefits in both non-diseased adults and breast cancer survivors [17, 18, 21, 22], we hypothesized that participants would improve (e.g., greater accuracy, faster response time) in domains of processing speed and spatial working memory after exercise compared with after rest. We also sought to examine how regular PA may have influenced the relationship between acute exercise and cognitive function. Due to the heavily documented positive effects of chronic exercise on cognition across the lifespan [18], we hypothesized that women who engaged in higher levels of regular PA would exhibit greater performance compared with their less active counterparts.

\section{Methods}

\section{Participants}

Community-dwelling breast cancer survivors were recruited to participate in a randomized, crossover study assessing the effects of acute exercise on cognitive functioning. Recruitment efforts included local media, the local university e-newsletter, and family, friend, and Carle Foundation Hospital oncologist referral. Eligibility criteria required participants to be: female; between the ages of 30 and 60; a physician-confirmed breast cancer survivor (stages DCIS-IIIB); completed with primary treatment for breast cancer; capable of participation in maximal exercise as determined by their personal physician; free of dementia or organic brain syndrome; capable of walking unassisted; suffering from self-reported memory troubles after diagnosis/treatment; and free from other health reasons contraindicating exercise. Participant flow through the study is detailed in Fig. 1. The trial ran from October 2015 to April 2016, the scheduled date of closure. All methods and procedures were approved by the institutional review board (IRB; ethics committee) at the University of Illinois at Urbana-Champaign, conducted in Urbana, IL, and written informed consent was obtained from all individual participants included in the study.

\section{Procedures}

Participants completed three appointments. The first consisted of a graded maximal exercise test to determine maximal heart rate. At the second and third appointments, participants completed 30 min of either exercise or rest with pre- and post- cognitive function measures. These two sessions were counterbalanced using block randomization (1:1 allocation ratio; block size of 4 ) after passed prescreening to control for potential learning and/or practice effects on the cognitive tasks. The primary study investigator generated the random allocation sequence, and the first author enrolled and assigned participants to interventions.

\section{Aerobic exercise session}

The aerobic session consisted of two rounds of cognitive tasks as well as a 30-min bout of moderate-intensity aerobic exercise. Upon arrival, participants completed the battery of cognitive tasks (detailed later) in a quiet, distraction-free room. Upon completion of the cognitive battery, individuals were fitted with a heart rate monitor and briefed on the aerobic walking session. Participants 


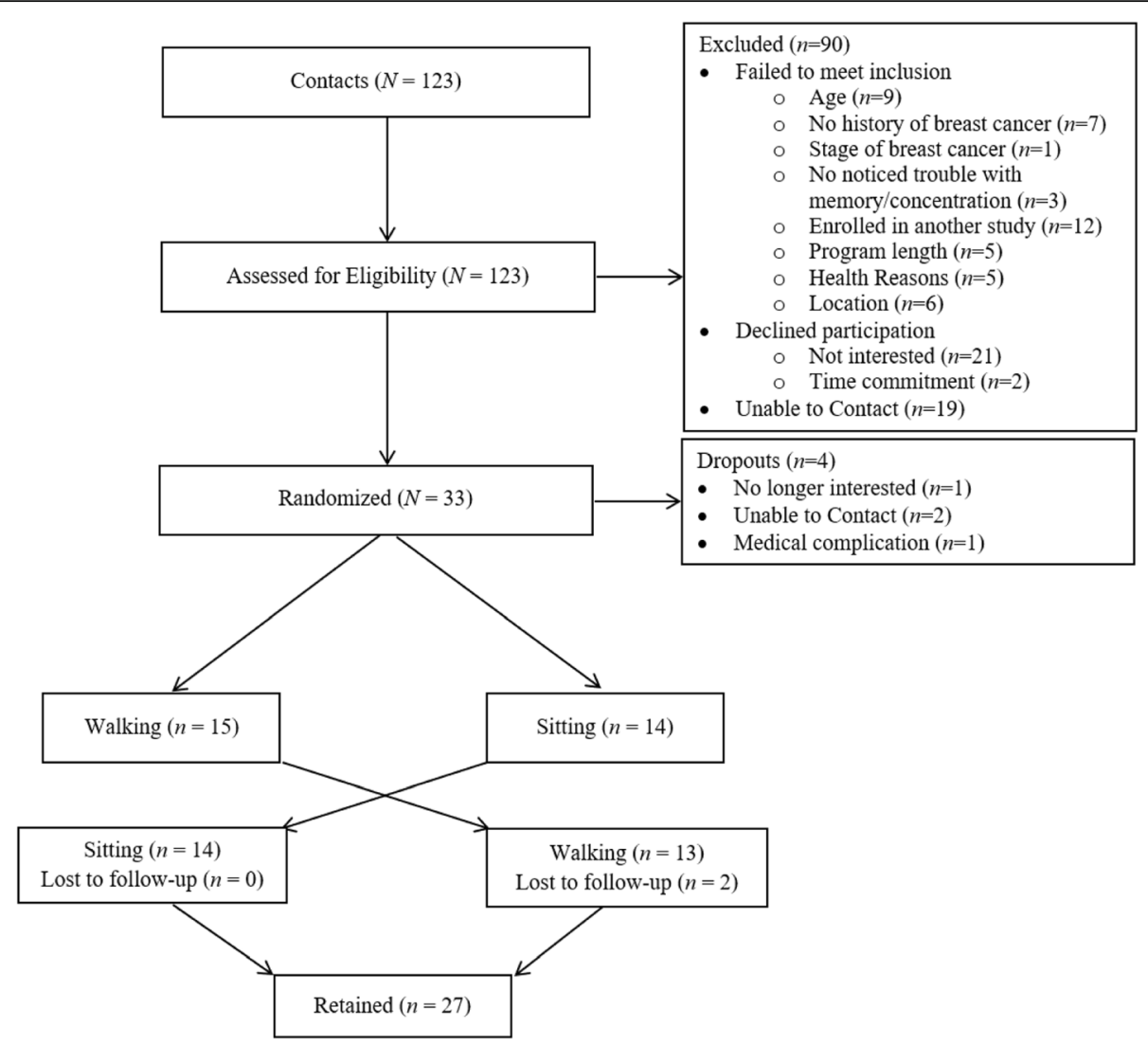

Fig. 1 CONSORT. Detailed flow of participants through the study

were instructed to walk on a treadmill at $40-60 \%$ of their maximal heart rate (HR) as determined by their individual graded exercise test. Treadmill speed and/or elevation were defined through a cooperative effort from both the participant and trained exercise specialist to ensure the appropriate HR range as well as participant comfort and safety. To account for varying heart rates that may have prevented participants from achieving the desired range (e.g., use of beta blocker medications), participants also maintained a rating of perceived exertion (RPE) between 8 and 11 throughout the $30 \mathrm{~min}$ [29]. This session began and ended with a 2-min warm-up and cool-down period, respectively. To prevent the potential confounding influence of social interaction between the participant and exercise leader, talking was kept to a minimum. HR, RPE, and blood pressure (BP) were measured before, during, and after the session as needed for safety. Upon completion, participants removed the heart rate monitor and repeated the cognitive battery.

\section{Seated rest session}

The seated resting session consisted of two rounds of the cognitive tasks as well as a 30-min period of seated rest. Upon arrival, participants completed the cognitive battery in the same quiet, distraction-free room. Once completed, participants were fitted with a heart rate monitor and instructed to remain seated for $30 \mathrm{~min}$ with the option to watch a television show. They were told to refrain from talking, reading, using their phones or falling asleep. HR, $\mathrm{RPE}$, and BP were assessed before, during, and after the session. Upon completion, participants completed their second cognitive battery.

\section{Measures \\ Demographics \& health history}

Participants self-reported age, race, education, income, education and breast cancer diagnostic history. Body mass index (BMI) was assessed via height and weight measurements taken on a calibrated stadiometer at the first appointment.

\section{Cognitive battery}

The cognitive battery was delivered immediately before and after each exercise and resting session and was comprised of the following tasks: processing speed and spatial working memory (described in detail below). All task instructions were presented for participants to read followed by a practice round. Response accuracy feedback was given during practice rounds only. A trained staff member was present in the room for all practices to answer any questions and 
troubleshoot comprehension issues. The staff member then exited the room before the trial began.

\section{Letter comparison task}

The letter comparison task was used to measure processing speed. This paper and pencil task consisted of two pages containing strings of consonants separated by a line (ex: TGL _ YGL) [30]. Participants were asked to classify the pairs as either "same" or "different" by writing an "S" or " $\mathrm{D}$ " on the line as appropriate. They were encouraged to work in order from the top of the page to the bottom as quickly and accurately as possible. Each page was timed separately. Outcome variables from this test were accuracy (e.g., percentage of correct responses) and reaction time (e.g., length of time taken to complete the task).

\section{Spatial working memory task}

The spatial working memory task was a computer-based cognitive task requiring participants to focus on a cross in the middle of a white screen. Two, 3, or 4 black dots appeared on the screen for a duration of 500 milliseconds (ms) before disappearing. A red dot then appeared for $2000 \mathrm{~ms}$ [31]. Participants were asked to indicate whether the location of the red dot matched one of the previous black dot locations using keys on a keyboard ("M" for match or "X" for no match) as quickly and accurately as possible. Outcome variables were accuracy (e.g., percentage of correct responses) and reaction time (e.g., length of time taken to respond) for each of the trials (2-item: 2 dots; 3-item: 3 dots; 4-item: 4 dots).

\section{Physical activity}

PA was assessed objectively via accelerometry using Actigraph brand accelerometers (Actigraph, Pensacola, FL: model GT3X). Each participant was instructed to wear her accelerometer for seven consecutive days on her non-dominant hip during all waking hours and record the time worn on a log sheet. Data were scored with an interruption period of $60 \mathrm{~min}$, and all data retained for analyses met at least $10 \mathrm{~h}$ of wear time on at least 3 days [32]. Accelerometry data were then downloaded as activity counts representing raw accelerations summed over a 1-s epoch length that varied based on intensity and frequency of the accelerations [33]. All downloaded data were then analyzed in ActiLife (Version 6; Actigraph, Pensacola, FL) using adult-specific intensity (counts/minute) cut-points [34]. To determine average daily moderate-to-vigorous physical activity (MVPA), the number of minutes spent engaging in MVPA was divided by the total number of valid days worn per participant. For the analyses reported herein, we used a median split of average daily MVPA (e.g., < $45 \mathrm{~min}$ and $\geq 45 \mathrm{~min}$ ) to identify differences in cognitive outcomes between regular exercisers and their less active counterparts.

\section{Data analysis}

Twenty-four participants provided $80 \%$ power assuming a 0.05 alpha to detect a moderately-sized effect (i.e., $\eta^{2} \geq .07$ ) from pre- to post-session between exercise and rest. Cohen's D effect sizes were also calculated. Defined as the standardized difference between treatment and comparison group means [35], effect sizes are independent of sample size and thus may be better indicators of group differences than traditional $p$ values [36]. It remains unclear if such a change in cognitive reaction time and accuracy is clinically meaningful in breast cancer survivors; however, there are currently no studies examining the effects of acute aerobic exercise on cognitive function in this cancer cohort. Findings from this study will provide effect sizes for future work replicating these efforts.

All analyses were conducted in SPSS (Version 22; Chicago, IL). Initial analyses used two (session) by two (time) repeated measures analyses of variance to examine the effects of the two sessions on processing speed and spatial working memory. Given that the design of this study exposed participants to both the exercise and resting sessions, time (e.g., pre- and post-session) and session (e.g., exercise and rest) were included as within-subjects factors to allow each subject to act as her own "control". We then used the average daily MVPA median split as a between-subjects factor to examine the differential effects of acute exercise on cognition by regular MVPA status (e.g., $\geq 45$ min MVPA/day vs. < 45 min MVPA/ day). Scores below $50 \%$ on accuracy outcomes were removed and considered missing. Such scores are worse than chance making it likely that participants either did not comprehend the task or were guessing, resulting in an unreliable score. As such, if a participant's score for accuracy was below this threshold for one session, her other session was marked missing as well. Final sample sizes for each cognitive outcome are detailed in Figure legends.

\section{Results}

A total of 27 women completed all testing, $M_{\text {age }}=$ 49.11(8.05). Table 1 depicts sample and cancer-specific characteristics.

Briefly, participants were stage I or II survivors (75\%), recipients of chemotherapy $(82.1 \%)$, married $(70.4 \%)$, employed full-time (74.1\%), college educated (66.6\%), and Caucasian (100\%). Mean data (e.g., HR, BP, RPE) from the exercise and resting sessions are detailed in Table 2. No adverse events occurred through the duration of this project.

\section{Processing speed}

Our initial analyses comparing the differential effects of exercise and rest on processing speed revealed a significant time by session interaction for reaction time $\left[F(1,25)=5.02, p=.03, \eta^{2}=0.17\right]$, such that participants were significantly faster from pre- to 
Table 1 Sample Characteristics

\begin{tabular}{|c|c|}
\hline & $\begin{array}{l}\text { Mean (SD) or } \% \\
N=27\end{array}$ \\
\hline Age & $49.11(8.05)$ \\
\hline \multicolumn{2}{|l|}{ Cancer Stage } \\
\hline DCIS & $7.1 \%$ \\
\hline । & $39.3 \%$ \\
\hline$\|$ & $35.7 \%$ \\
\hline III & $17.9 \%$ \\
\hline Estrogen receptor positive & $71.4 \%$ \\
\hline \multicolumn{2}{|l|}{ Treatment } \\
\hline Chemotherapy & $82.1 \%$ \\
\hline Months since chemotherapy & $54.7(60.3)$ \\
\hline Radiation therapy & $75.0 \%$ \\
\hline Months since radiation therapy & $64.1(66.0)$ \\
\hline Surgery & $100 \%$ \\
\hline Months since surgery & $53.2(45.4)$ \\
\hline \multicolumn{2}{|l|}{ Marital Status } \\
\hline Married & $70.4 \%$ \\
\hline \multicolumn{2}{|l|}{ Employment Status } \\
\hline Full Time (> 35 h/wk) & $74.1 \%$ \\
\hline \multicolumn{2}{|l|}{ Race } \\
\hline White & $100 \%$ \\
\hline \multicolumn{2}{|l|}{ Highest Level of Education } \\
\hline$>$ College Degree & $66.6 \%$ \\
\hline \multicolumn{2}{|l|}{ Annual Household Income } \\
\hline$<\$ 45,000$ & $18.5 \%$ \\
\hline$\leq \$ 90,000$ & $14.8 \%$ \\
\hline$>\$ 90,000$ & $37.0 \%$ \\
\hline Chose not to answer & $29.6 \%$ \\
\hline \multicolumn{2}{|l|}{ Body Mass Index (BMI) } \\
\hline Normal Weight & $34.6 \%$ \\
\hline Overweight & $30.8 \%$ \\
\hline Obese & $34.6 \%$ \\
\hline
\end{tabular}

SD standard deviation, DCIS ductal carcinoma in situ post-exercise $(p=.02)$ compared with no change from pre- to post-rest $(\mathrm{p}=.33)$ as shown in Fig. $2(d=.25)$. Further between-subjects analyses indicated a significant time by session by MVPA interaction [F $(1,25)=$ $5.23, p=.03, \eta 2=.17]$. This was driven by more significantly faster reaction time from pre- to post-exercise $(p=.01)$ in women with at least $45 \mathrm{~min}$ of MVPA/day $(n=13)$ compared with slower reaction time from pre- to post-rest $(p=.06)$ as shown in Fig. 3 $(d=.65)$. There were no significant changes in reaction time after either session (e.g., exercise, rest) for women engaging in less than $45 \mathrm{~min}$ of MVPA per day $(n=14)$. There was no significant time by session interaction for accuracy $(p=.44)$, thus between-subjects analyses for MVPA were not explored.

\section{Spatial working memory}

Analyses comparing the differential effects of exercise and rest on spatial working memory revealed a time by session interaction that trended towards significance for 3-item response accuracy $\left[F(1,26)=3.36, p=.08, \eta^{2}=0.12\right]$. This effect was explained by increased accuracy post-exercise compared with reduced accuracy post-resting session $(d=$ 0.48 ) as shown in Fig. 4. The time by session interaction for 4-item reaction time was also nonsignificant $[\mathrm{F}(1,23)=2.93$, $\left.p=.10, \eta^{2}=0.11\right]$, but trended towards reduced reaction time post-exercise session compared with no change in reaction time post-resting session $(d=0.29)$ as shown in Fig. 4. Further between-subjects analyses for MVPA were not significant $(p=.33)$.

\section{Discussion}

The purpose of this study was to examine whether acute bouts of exercise and rest differentially influenced processing speed and spatial working memory in breast cancer survivors. Although there is evidence for the use of exercise in improving varying domains of physical and mental health in breast cancer survivors [26, 27], this study is the first, to our knowledge, to examine the immediate effects of moderate-intensity exercise on domains of cognitive functioning in breast cancer. In the present study, there was a significant time by session interaction for processing speed reaction time and a

Table 2 Mean Data from Aerobic \& Resting Sessions

\begin{tabular}{lll}
\hline & $\begin{array}{l}\text { Exercise Session } \\
\text { Mean (SD) } \\
N=27\end{array}$ & $\begin{array}{l}\text { Resting Session Mean (SD) } \\
N=27\end{array}$ \\
\hline Heart Rate (bpm) & $103.70(12.15)$ & $74.33(13.09)$ \\
Systolic Blood Pressure $(\mathrm{mmHg})$ & $123.77(13.20)$ & $108.00(11.13)$ \\
Diastolic Blood Pressure (mmHg) & $74.15(7.37)$ & $71.00(8.04)$ \\
Rating of Perceived Exertion & $8.74(1.93)$ & $6.11(0.32)$ \\
Time Between Session and Cognitive Tasks (min) & $5.07(1.38)$ & $2.28(1.10)$ \\
\hline
\end{tabular}

SD standard deviation, bpm beats per minute, $\mathrm{mmHg}$ millimeter of mercury 


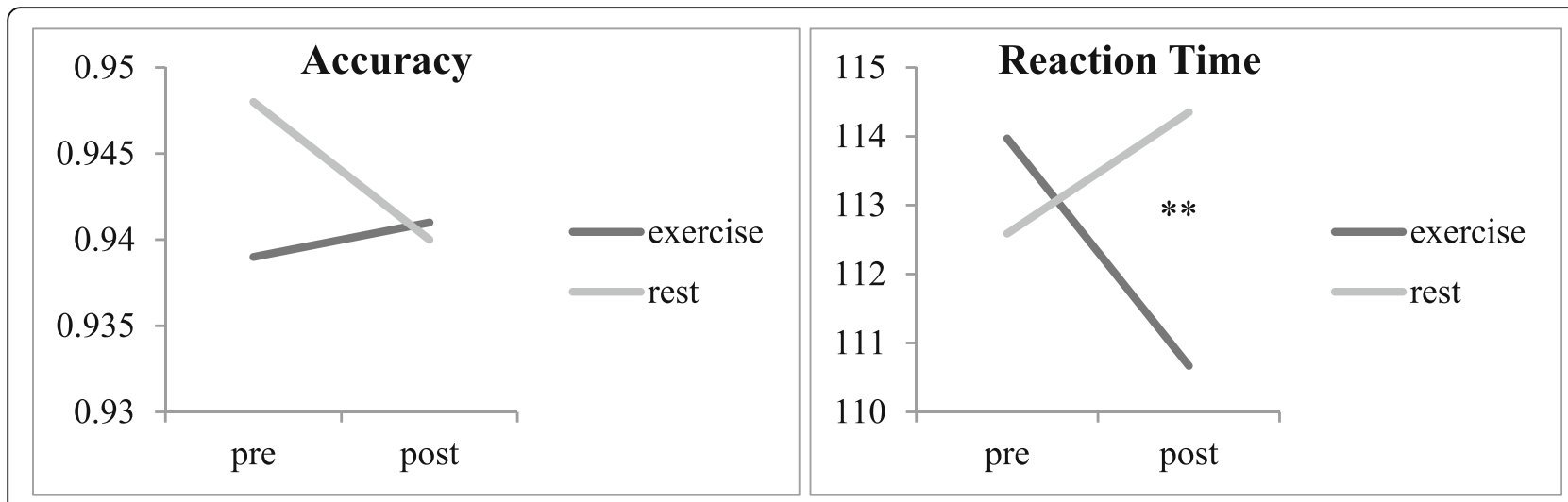

Fig. 2 Processing speed changes across time and session. Accuracy $n=27$; Reaction Time $n=26$. * significant at $p<.05$

time by session interaction that trended towards significance for spatial working memory accuracy. Notably, the effect sizes for these interactions ranged from small $(d$ $=.25)$ to moderate $(d=.65)$ in favor of exercise, suggesting that the results reported herein are indeed meaningful for future work. Importantly, these findings are within the context of a single walking session: an achievable method with the capacity for real world translation beyond a cancer diagnosis. However, we acknowledge that this is nascent research in a small sample and further work exploring acute exercise effects on cognition after cancer is warranted.

Our analyses examining differential effects of exercise and rest on processing speed demonstrated a significant time by session effect for reaction time such that women displayed reduced reaction time (e.g., performed faster) after exercise compared with no change in reaction time after rest. Response accuracy after each session remained unchanged ( $p s>38$ ), suggesting that women performed faster after exercise without sacrificing accuracy. Given that there are no comparable studies in the literature examining the effects of acute exercise of cognition in breast cancer survivors with which to make comparisons, we discuss the current results relative to previous research in healthy adults. Indeed, these findings are consistent with the acute exercise literature such that individuals benefit from acute exercise in significantly improved reaction time but not response accuracy [24, 37]. McMorris and colleagues [38] have previously discussed the inherent discrepancy between the cognitive nature of the task and the motoric response required, possibly explaining the differential effects of acute exercise on speed and accuracy. After replicating these findings on a larger scale, further work examining the underlying biological pathways contributing to these differential effects of exercise on cognitive outcome variables in breast cancer survivors is necessary.

Of further interest is the moderating effect of chronic MVPA on the relationship between acute exercise and processing speed. In the current study, women who accumulated at least 45 min of MVPA per day on average performed significantly faster on the processing speed task after exercise compared with their less active counterparts $(d=.65)$. The moderate magnitude of this effect suggests that the influence of chronic MVPA on the relationship between acute exercise and cognition in breast cancer is meaningful. This finding supports the well-documented relationship between regular PA engagement and improved

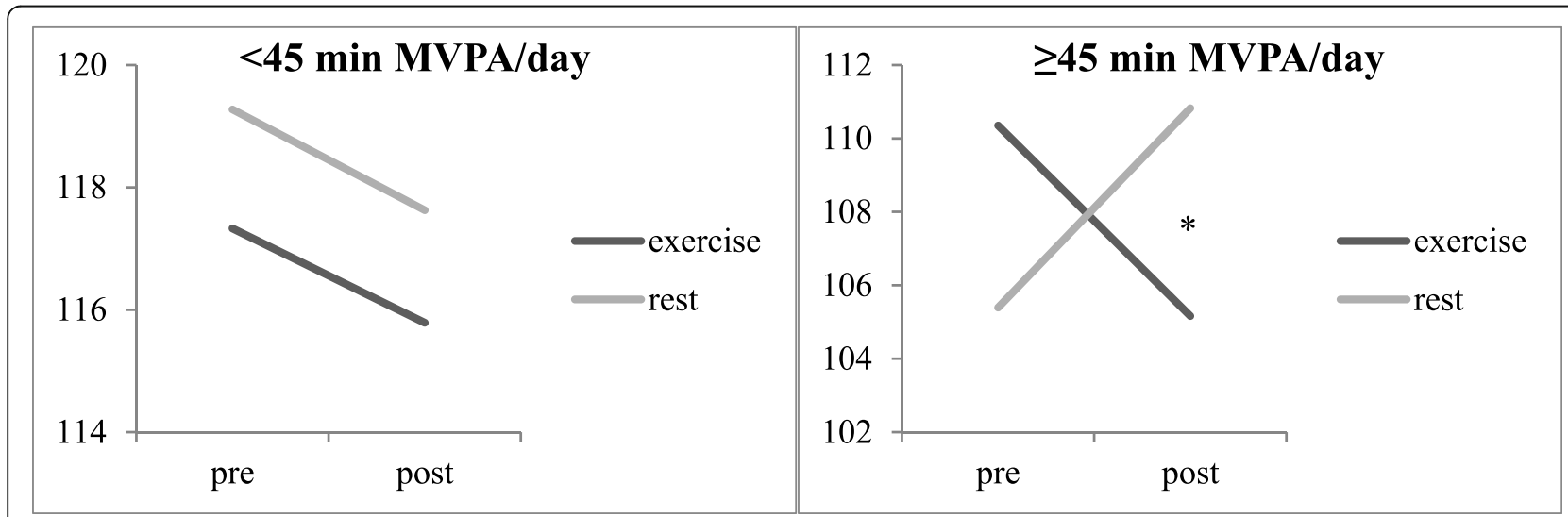

Fig. 3 Processing speed reaction time changes across time, session, and MVPA split. Accuracy $n=27$; Reaction Time $n=26$. * significant at $p=.01$ 


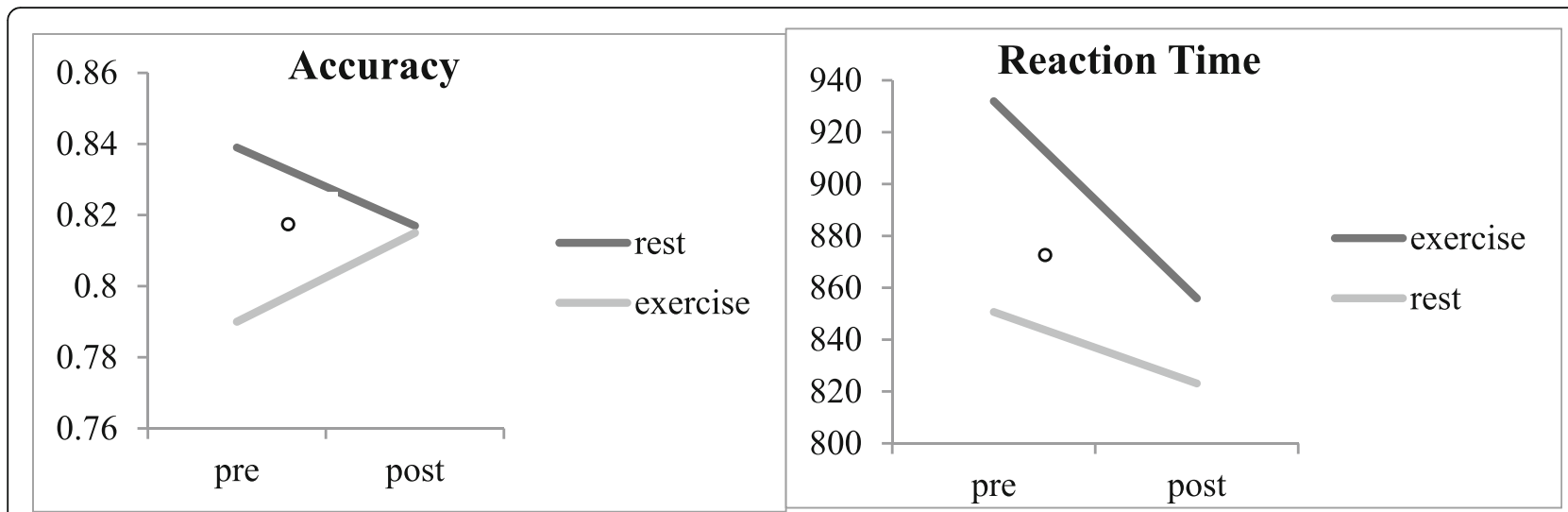

Fig. 4 Spatial working memory changes across time and session. 3-item Accuracy $n=27$; 4 -item Reaction Time $n=24 .{ }^{\circ}$ trend at $.08<p<.10$.

cognition in healthy individuals across the lifespan [39-41], suggesting that breast cancer survivors may be amenable to similar cognitive benefits through exercise. It is also possible that $30 \mathrm{~min}$ was too long an exercise duration for women who were not regular exercisers, despite its moderate intensity. While all acute sessions were individualized to the women's fitness levels, fatigue may have been a contributing factor for those who were deconditioned and/or more sedentary [25]. Future research might explore potential dose-response effects of exercise duration and/or intensity on cognition to determine the optimal length of exercise in this cancer cohort.

Interestingly, while women who accumulated at least $45 \mathrm{~min}$ of MVPA/day had faster reaction after walking for $30 \mathrm{~min}$, their performance trended slower after sitting. This may be due to the control condition (television viewing) of the present study. Indeed, there is a growing body of literature highlighting the negative influence of television viewing/screen time on varying domains of cognition across the lifespan [37, 42, 43]. While this context is likely a good proxy for real-world sedentary behavior, it will be important for future research to include other control conditions (e.g., reading, socializing) to further tease out the effects of acute exercise on cognition after cancer.

In addition to improving processing speed, women in the present study marginally improved response accuracy on a spatial working memory task immediately after acute exercise. This finding contrasts previous work in healthy adults demonstrating small to moderate decrements in accuracy post-exercise [24]. It may be that breast cancer survivors have more room for accuracy improvements in certain cognitive domains after acute exercise, particularly if they are starting at lower levels of cognition prior to lifestyle intervention. Notably, participants in the current study were eligible if they self-reported noted trouble with memory or concentration after their cancer experience, therefore they may have had more room for improvement than the population level of breast cancer survivors. Although statistically nonsignificant $(p=.08)$, the effect size for the time by session effect on spatial working memory accuracy was moderate in scale $(d=.48)$. Effect sizes are independent of sample size and thus are considered better indicators of group differences than traditional $p$ values [36]. In this case, the magnitude of the effect suggests that exercise may have a meaningful influence on spatial working memory, an important implication for future intervention designs targeting cognitive health in breast cancer survivors.

These findings are timely given the burgeoning interest in acute exercise on a national level [23]. With a growing body of literature suggesting beneficial effects of chronic exercise on cognition in healthy individuals, it will be important to consider the role of acute exercise in this relationship. There is evidence for differential effects of acute and chronic exercise on cognitive and affective outcomes [44], which is critical for informing behavioral change interventions. It's important that future work disentangle their confluence, specifically within the context of cancer and its heterogeneous manifestation. While we present nascent work in a small sample of breast cancer survivors, these findings suggest that acute exercise may be a complementary area of research worth exploring in tandem with long-term PA for sustained cognitive health and quality of life during survivorship.

There are several limitations to the present study. The sample size was small and comprised of white, highly educated women, therefore findings are certainly not generalizable across all breast cancer survivors. Given cancer's wide-ranging presentation and consequential disparities that exist across the continuum, future work should target a larger, more demographically diverse sample. In addition, these results are specific to post-treatment survivors. Knowing that CRCI exists across the entirety of the cancer continuum, it will be important to determine how acute exercise may be leveraged for cognitive health both prior to and during treatment as well as within different subgroups of cancer and treatment regimens. 
It is possible that the findings herein may be magnified in women undergoing treatment with higher levels of CRCI [15]. However, it is nevertheless exciting that acute exercise has the capacity to significantly improve cognition in a sample of breast cancer survivors that is, on average, $\sim 4.5$ years post-treatment. Similarly, these findings are relevant to only two domains of cognitive function. Understanding the effects of acute exercise on other domains of executive functioning such as attention or cognitive flexibility will be important. More research is warranted to replicate and extend the findings reported herein to provide greater insight into the relationship between acute exercise and cognition in cancer survivors.

\section{Conclusions}

Despite these limitations, 30 min of walking may be a better choice than sitting for at least maintaining, if not improving, important domains of cognitive functioning in breast cancer survivors. As the population continues to age and more individuals live beyond their cancer diagnosis, it will become increasingly important to understand and prevent its deleterious health effects. Cancer-related cognitive impairment remains largely misunderstood; however, results from the present study offer preliminary evidence for the positive association between acute exercise and cognitive function in breast cancer survivors.

\section{Abbreviations}

BCS: Breast cancer survivors; BMI: Body mass index; BP: Blood pressure; DCIS: Ductal carcinoma in situ; HR: Heart rate; IRB: Institutional review board; ms: milliseconds; MVPA: Moderate-vigorous physical activity; PA: Physical activity; RPE: Rating of perceived exertion; SD: Standard deviation

\section{Acknowledgements}

The authors would like to acknowledge and thank Janet Iverson for her invaluable recruitment assistance. This work was also supported by a Shahid and Ann Carlson Khan endowed professorship awarded to EM.

\section{Funding}

N/A

\section{Availability of data and materials}

The datasets used and/or analyzed during the current study are available from the corresponding author on reasonable request.

\section{Authors' contributions}

$E S, K R, A F$ and $E M$ made substantial contributions to conception and design. ES acquired, analyzed, and interpreted the data. ES and EM drafted the initial manuscript. RK, AF and EM revised the manuscript critically for important intellectual content. All authors read and approved the final manuscript.

\section{Ethics approval and consent to participate}

All methods and procedures were approved by the institutional review board (IRB; ethics committee) at the University of Illinois at UrbanaChampaign, and written informed consent was obtained from all individual participants included in the study.

\section{Consent for publication}

N/A

\section{Competing interests}

The authors declare that they have no competing interests.

\section{Publisher's Note}

Springer Nature remains neutral with regard to jurisdictional claims in published maps and institutional affiliations.

\author{
Author details \\ ${ }^{1}$ Cancer Prevention Fellowship Program, Division of Cancer Epidemiology \& \\ Genetics, Metabolic Epidemiology Branch, National Cancer Institute, \\ Bethesda, MD 20892, USA. ${ }^{2}$ University of Illinois at Urbana-Champaign, \\ Champaign, USA. ${ }^{3}$ Carle Foundation Hospital, Urbana, USA. ${ }^{4}$ Northeastern \\ University, Boston, USA.
}

Received: 24 September 2018 Accepted: 9 April 2019

Published online: 23 April 2019

\section{References}

1. Siegel RL, Miller KD, Jemal A. Cancer statistics, 2015. CA Cancer J Clin. 2015; 65(1):5-29. https://doi.org/10.3322/caac.21254.

2. Carlson RW, Allred DC, Anderson BO, et al. Breast cancer. Clinical practice guidelines in oncology. J Natl Compr Cancer Netw. 2009;7(2): 122-92 http://www.ncbi.n/m.nih.gov/pubmed/19200416. Accessed 11 Mar 2016.

3. DeSantis C, Ma J, Bryan L, Jemal A. Breast cancer statistics, 2013. CA Cancer J Clin. 64(1):52-62. https://doi.org/10.3322/caac.21203.

4. Abe $\mathrm{O}$, Abe R, Enomoto $\mathrm{K}$, et al. Effects of chemotherapy and hormonal therapy for early breast cancer on recurrence and 15-year survival: an overview of the randomised trials. Lancet. 2005;365(9472): 1687-717. https://doi.org/10.1016/S0140-6736(05)66544-0.

5. Clarke $M$, Collins R, Darby $S$, et al. Effects of radiotherapy and of differences in the extent of surgery for early breast cancer on local recurrence and 15-year survival: an overview of the randomised trials. Lancet (London, England). 2005;366(9503):2087-106. https:// doi.org/10.1016/S0140-6736(05)67887-7.

6. Ganz PA, Kwan L, Stanton AL, et al. Quality of life at the end of primary treatment of breast Cancer: first results from the moving beyond Cancer randomized trial. JNCI J Natl Cancer Inst. 2004;96(5):376-87. https://doi.org/ 10.1093/jnci/djh060.

7. Darby SC, Ewertz M, McGale P, et al. Risk of ischemic heart disease in women after radiotherapy for breast Cancer. N Engl J Med. 2013;368(11): 987-98. https://doi.org/10.1056/NEJMoa1209825.

8. Ferguson RJ, Riggs R, Ahles T, Saykin AJ. Management of Chemotherapy-Related Cognitive Dysfunction. In: Handbook of Cancer survivorship. Boston, MA: Springer US; 2007:287-301. doi:https:/doi.org/10.1007/978-0-387-34562-8_16.

9. McMorris T, Mackenzie MJ, Zuniga KE, McAuley E. Chapter 19 - cognitive impairment in breast Cancer survivors: the protective role of physical activity, cardiorespiratory fitness, and exercise training. Exercise-Cognition Interaction. 2016:399-419. https://doi.org/10.1016/B978-0-12-800778-5.00019-0.

10. Diamond A. Executive functions. Annu Rev Psychol. 2013;64:135-68. https:// doi.org/10.1146/annurev-psych-113011-143750.

11. van Harten WH, van Noort O, Warmerdam R, Hendricks H, Seidel E. Assessment of rehabilitation needs in cancer patients. Int J Rehabil Res. 1998;21(3):247-57 http://www.ncbi.nlm.nih.gov/pubmed/9812254. Accessed 2 Dec 2013.

12. Goodwin JS, Samet JM, Hunt WC. Determinants of survival in older cancer patients. J Natl Cancer Inst. 1996;88(15):1031-8 http://www.ncbi.nlm.nih. gov/pubmed/8683633. Accessed 2 Dec 2013.

13. Pinto AC, de Azambuja E. Improving quality of life after breast cancer: dealing with symptoms. Maturitas. 2011;70(4):343-8. https://doi.org/10.1016/ j.maturitas.2011.09.008

14. Kesler S, Hadi Hosseini SM, Heckler $\mathrm{C}$, et al. Cognitive training for improving executive function in chemotherapy-treated breast cancer survivors. Clin Breast Cancer. 2013;13(4):299-306. https://doi.org/10.1016/j.clbc.2013.02.004.

15. Janelsins MC, Kesler SR, Ahles TA, Morrow GR. Prevalence, mechanisms, and management of cancer-related cognitive impairment. Int Rev Psychiatry. 2014;26(1):102-13. https://doi.org/10.3109/09540261.2013.864260.

16. Ahles TA, Root JC, Ryan EL. Cancer- and cancer treatment-associated cognitive change: an update on the state of the science. J Clin Oncol. 2012; 30(30):3675-86. https://doi.org/10.1200/JCO.2012.43.0116.

17. Mandelblatt JS, Hurria A, McDonald BC, et al. Cognitive effects of cancer and its treatments at the intersection of aging: what do we know; what do we need to know? Semin Oncol. 2013;40(6):709-25. https://doi.org/10.1053/ j.seminoncol.2013.09.006. 
18. Hillman $\mathrm{CH}$, Erickson $\mathrm{Kl}$, Kramer AF. Be smart, exercise your heart: exercise effects on brain and cognition. Nat Rev Neurosci. 2008;9(1):5865. https://doi.org/10.1038/nrn2298.

19. Zimmer $P$, Baumann FT, Oberste $M$, et al. Effects of exercise interventions and physical activity behavior on Cancer related cognitive impairments: a systematic review. Biomed Res Int. 2016;2016:1820954. https://doi.org/10.1155/2016/1820954.

20. Derry HM, Jaremka LM, Bennett JM, et al. Yoga and self-reported cognitive problems in breast cancer survivors: a randomized controlled trial. Psychooncology. 2015;24(8):958-66. https://doi.org/10.1002/pon.3707.

21. Leach HJ, Danyluk JM, Nishimura KC, Culos-Reed SN. Evaluation of a community-based exercise program for breast Cancer patients undergoing treatment. Cancer Nurs. 2015;38(6):417-25. https://doi.org/ 10.1097/NCC.0000000000000217.

22. Irwin ML, McTiernan A, Bernstein L, et al. Physical activity levels among breast cancer survivors. Med Sci Sports Exerc. 2004;36(9): 1484-91 http://www.ncbi.nlm.nih.gov/pubmed/15354027. Accessed 16 Dec 2016

23. Piercy KL, Troiano RP, Ballard RM, et al. The physical activity guidelines for Americans. JAMA. 2018;320(19):2020. https://doi.org/10.1001/jama.2018.14854.

24. McMorris T, Sproule J, Turner A, Hale BJ. Acute, intermediate intensity exercise, and speed and accuracy in working memory tasks: a metaanalytical comparison of effects. Physiol Behav. 2011;102(3-4):421-8. https:// doi.org/10.1016/j.physbeh.2010.12.007.

25. Chang YK, Labban JD, Gapin Jl, Etnier JL. The effects of acute exercise on cognitive performance: a meta-analysis. Brain Res. 2012;1453:87-101. https:// doi.org/10.1016/j.brainres.2012.02.068.

26. Blacklock R, Rhodes R, Blanchard C, Gaul C. Effects of exercise intensity and self-efficacy on state anxiety with breast Cancer survivors. Oncol Nurs Forum. 2010;37(2):206-12. https://doi.org/10.1188/10.ONF.206-212.

27. Blanchard CM, Courneya KS, Laing D. Effects of acute exercise on state anxiety in breast cancer survivors. Oncol Nurs Forum. 28(10):1617-1621. http://europepmc.org/abstract/med/11759309. Accessed 21 Jan 2016.

28. Evans ES, Hackney AC, McMurray RG, et al. Impact of acute intermittent exercise on natural killer cells in breast Cancer survivors. Integr Cancer Ther. 2015:14(5):436-45. https://doi.org/10.1177/1534735415580681.

29. Borg, Gunnar. Borg's perceived exertion and pain scales. Human Kinetics; 1998.

30. Salthouse TA, Babcock RL. Decomposing adult age differences in working memory. Dev Psychol. 1991;27(5):763-76. https://doi.org/10.1037/0012-1649.27.5.763.

31. Erickson Kl, Voss MW, Prakash RS, et al. Exercise training increases size of hippocampus and improves memory. Proc Natl Acad Sci U S A. 2011;108(7): 3017-22. https://doi.org/10.1073/pnas.1015950108.

32. Troiano RP, Berrigan D, Dodd KW, Mâsse LC, Tilert T, McDowell M. Physical activity in the United States measured by accelerometer. Med Sci Sports Exerc. 2008;40(1):181-8. https://doi.org/10.1249/mss.0b013e31815a51b3.

33. Sasaki JE, John D, Freedson PS. Validation and comparison of ActiGraph activity monitors. J Sci Med Sport. 2011;14(5):411-6. https://doi.org/10.1016/j.jsams.2011.04.003.

34. Freedson PS, Melanson E, Sirard J. Calibration of the computer science and applications, Inc. accelerometer. Med Sci Sports Exerc. 1998;30(5):777-81. https://doi.org/10.1097/00005768-199805000-00021.

35. Cohen J. Statistical power analysis for the behavioral sciences. Hillsdale, NJ: Larence Earlbaum Associates; 1988.

36. Sullivan $G M$, Feinn $R$. Using effect size-or why the $P$ value is not enough. J Grad Med Educ. 2012;4(3):279-82. https://doi.org/10.4300/JGME-D-12-00156.1.

37. Tomporowski PD. Effects of acute bouts of exercise on cognition. Acta Psychol. 2003;112(3):297-324 http://www.ncbi.nlm.nih.gov/pubmed/ 12595152. Accessed 3 Apr 2016.

38. McMorris T, Collard K, Corbett J, Dicks M, Swain JP. A test of the catecholamines hypothesis for an acute exercise-cognition interaction. Pharmacol Biochem Behav. 2008;89(1):106-15. https://doi.org/10.1016/j.pbb.2007.11.007.

39. Sibley BA, Etnier JL. The relationship between physical activity and cognition in children: a meta-analysis. Pediatr Exerc Sci. 2003;15(3):243-56. https://doi.org/10.1123/pes.15.3.243

40. Hillman CH, Belopolsky AV, Snook EM, Kramer AF, McAuley E. Physical activity and executive control: implications for increased cognitive health during older adulthood. Res Q Exerc Sport. 2004;75(2):176-85. https://doi. org/10.1080/02701367.2004.10609149.

41. Kramer AF, Erickson Kl, Colcombe SJ. Exercise, cognition, and the aging brain. J Appl Physiol. 2006;101(4).

42. McMorris T, Hale BJ. Differential effects of differing intensities of acute exercise on speed and accuracy of cognition: a meta-analytical investigation. Brain Cogn. 2012;80(3):338-51. https://doi.org/10.1016/j. bandc.2012.09.001.

43. Drollette ES, Shishido T, Pontifex MB, Hillman CH. Maintenance of cognitive control during and after walking in preadolescent children. Med Sci Sports Exerc. 2012;44(10):2017-24. https://doi.org/10.1249/MSS.0b013e318258bcd5. 44. Hopkins ME, Davis FC, VanTieghem MR, Whalen PJ, Bucci DJ. Differential effects of acute and regular physical exercise on cognition and affect. Neuroscience. 2012;215:59-68. https://doi.org/10.1016/J.NEUROSCIENCE.2012.04.056.

\section{Ready to submit your research? Choose BMC and benefit from:}

- fast, convenient online submission

- thorough peer review by experienced researchers in your field

- rapid publication on acceptance

- support for research data, including large and complex data types

- gold Open Access which fosters wider collaboration and increased citations

- maximum visibility for your research: over $100 \mathrm{M}$ website views per year

At BMC, research is always in progress.

Learn more biomedcentral.com/submissions 